Molon, S. I.

"Algumas questões epistemológicas e éticas da psicologia: a avaliação em discussão"

\title{
ALGUMAS QUESTÕES EPISTEMOLÓGICAS E ÉTICAS DA PSICOLOGIA: A AVALIAÇÃO EM DISCUSSÃO
}

Susana Inês Molon

Fundação Universidade Federal de Rio Grande

RESUMO: Este trabalho pretende fazer uma reflexão sobre alguns dilemas epistemológicos e éticos que encontramos na produção do conhecimento psicológico frente à racionalidade hegemônica que institui um modelo de produção, de aplicação e de avaliação do conhecimento para a educação e para os programas de Pós-graduação, sobretudo da Psicologia. Para entendermos a condição presente da Psicologia, recorremos ao seu passado, buscando os indícios da sua história de luta e resistência, os registros de permanência e de rupturas, para que possamos pensar prospectivamente sobre nossa condição e nosso devir. No esforço de sistematizar alguns pontos do debate, vamos abordar inicialmente as especificidades da produção do conhecimento da Psicologia; logo em seguida, enfatizaremos a crise da racionalidade hegemônica e a emergência de um novo paradigma na ciência, e finalizaremos com a discussão sobre a avaliação.

PALAVRAS-CHAVE: Psicologia, conhecimento e avaliação.

\section{SOME EPISTHEMOLOGICAL AND ETHICAL QUESTIONS IN PSYCHOLOGY: AVALIATION UNDER DISCUSSION}

ABSTRACT: This study reflects upon some episthemological and ethical dilemma we find in the psychological knowledge production facing the hegemonic rationality that establishes a model of production, application and evaluation of knowledge to education and to Post-Graduation programmes, above all in Psychology. In order to understand the present condition of Psychology, we revisited its past, searching for indication of its struggle and resistence history, searching marks of permanence and ruptures, so we could think prospectively about our condition and our becoming. In the effort to systematize some points of the discussion, we initially approach 
the specificities of Psychology knowledge production; then, we emphasize the hegemonic rationality crisis and the emergence of a new pradigm in science, and we conclude with the discussion on evaluation.

KEYWORDS: Psychology, knowledge and evaluation.

A ciência, a tecnologia, a arte e a política são produtos históricos da atividade humana, localizados no campo da história das batalhas sociais e das lutas de classe, como também na divisão social do trabalho. Nesse sentido, a produção do conhecimento (dos diferentes tipos de conhecimento) acontece em um cenário social, político, econômico, cultural determinado pelo modo de produção de uma sociedade específica. Em certos momentos históricos, ocorre a implantação e a consolidação de um modelo ${ }^{1}$ que se torna hegemônico na maneira de conceber, construir, aplicar e avaliar o conhecimento. No entanto, outros tipos de conhecimento, com diferentes modos de produção e implicações sociais e culturais, não deixam de existir, ou seja, várias perspectivas coexistem e disputam lugares, espaços e tempos, bem como resistem, sofrem alterações, ressurgem de forma transformada ou aparentemente diferente.

Atualmente ocorre um movimento de mudança, a transição paradigmática, ${ }^{2}$ no bojo das ciências humanas e sociais, no qual temos um arcabouço teórico e metodológico que nos qualifica nacional e internacionalmente. Porém, enfrentamos alguns dilemas e obstáculos, colocamos novas questóes epistemológicas vinculadas à pro-

1 A consolidação da ciência moderna enquanto modo hegemônico da racionalidade a racionalidade cognitiva-instrumental, originou um modelo global e totalitário de racionalidade científica que defende, de forma policiável, apenas um tipo único de conhecimento - o conhecimento científico - e um tipo único de aplicação - a aplicação técnica, Santos (1996, 1996a).

2 A ordem científica hegemônica - a racionalidade científica - encontra-se em um período de transição, motivada pela ambigüidade e complexidade do tempo científico presente e pelo tempo paradoxal evidenciado pela discrepância entre possibilidade técnica e impossibilidade política. A transição paradigmática caracterizada pela crise do paradigma dominante e a construção do paradigma emergente, Santos (1996), Montero (1994). 
Molon, S. I.

"Algumas questões epistemológicas e éticas da psicologia: a avaliação em discussão"

blemática ética e ontológica, como também tentamos reconhecer e legitimar nosso conhecimento nas várias dimensôes da sociedade, em cursos da graduação e da pós-graduação, junto às associações, às entidades, aos fóruns, às agencias de fomento à pesquisa estaduais e nacionais, a órgãos governamentais instituídos, como a CAPES e o $\mathrm{CNPq}$, e em outros grupos sociais e comunidades.

Nesse sentido, cabe-nos refletir sobre a avaliação por considerála uma questão crucial e necessária que envolve recursos públicos, sobre os quais a população tem o direito de ser informada, e as instituições de ensino, o dever de prestar contas, em uma relação de transparência dos investimentos e das condições de trabalho.

Debater a avaliação implica trazer para a discussão todo o processo e o movimento dos sujeitos e das instituições envolvidas, e também olhar o projeto educacional e suas políticas públicas. Assim, questionamos a política governamental do nosso País, especialmente seus compromissos nacionais e internacionais que têm repercussōes e conseqüências graves no cotidiano do sistema educativo. É fundamental considerar que qualquer processo de avaliação está comprometido com a discussão coletiva do projeto de universidade, sobretudo da universidade pública, gratuita e de qualidade.

Não temos a pretensão de esgotar essa discussão, mas sim de compartilharmos uma prática de reflexão. Sabemos que, sistematicamente, a CAPES e o CNPq vêm praticando a revisão dos critérios e procedimentos de avaliação instituídos na busca de novos indicadores e elementos instituintes que possam aprimorar os instrumentos de avaliação, introduzindo novas práticas, outros quesitos, procurando a relação entre os quesitos e os itens, não deixando escapar os principais aspectos julgados necessários.

Assim, não nos colocamos à margem nem excluídos do sistema instituído, mas queremos criar espaços de diálogo, possibilidades de revisão, campos de transformação dos modos dominantes do conhecer, que prima pela procura dos seus fundamentos seguros e das suas regras confiáveis para a sua produção e avaliação. Com isso, não estamos dizendo que não são necessários os fundamentos e as regras para a produção e a avaliação do conhecimento, como também não queremos eliminar os critérios e as normas dos mesmos, mas compreendemos a necessidade de uma outra política de avalia- 
ção do conhecimento psicológico que contemple a diversidade e a pluralidade dos conhecimentos produzidos.

Algumas questões relacionadas à produção do conhecimento devem-se à especificidade do campo da psicologia, sua configuração histórica, seus dilemas epistemológicos, sua natureza científica e suas práticas psicológicas. Diversos autores vêm trabalhando com as questôes epistemológicas da psicologia, dentre eles, destacam-se Figueiredo (1991, 1992, 1996), González Rey (1997, 1999), Montero (1994, 1996), Munné (1982, 1997), Vygotsky (1996, 2001). A articulação entre os aspectos epistemológicos e éticos é enfatizada por Sawaia (1995, 1998, 1999).

A Psicologia encontra-se em "crise", essa é uma expressão utilizada por vários autores, cujas idéias são diferenciadas pelos significados da palavra e pelos sentidos atribuídos às diversas tendências e correntes da psicologia e o grau de reconhecimento e validação da crise.

Para Figueiredo (1991), a crise caracteriza-se pela diversidade de posturas metodológicas e teóricas em permanente oposição, cabe entendê-las enquanto matrizes do pensamento psicológico que sustentam práticas teóricas $\mathrm{da}(\mathrm{s})$ psicologia(s) contemporânea(s). Assim, reconhece-as nas suas especificidades: científicas, não científicas e as com pretensões de ser. No entanto, Figueiredo (1996) observa que a maneira como é tratada a questão da cientificidade da psicologia é problemática, vista por muitos psicólogos como algo que não lhes diz respeito, enquanto para outros é um problema sério.

Para o autor, o que chama a atenção é que os pesquisadores que pretendiam construir a psicologia científica, os que faziam críticas ao projeto epistemológico moderno, submeteram-se aos padrôes impostos pela cientificidade, isto é, embora tendo presente a impossibilidade da universalidade e da objetividade da ciência, e da neutralidade e da universalidade da razão, os cientistas da psicologia pesquisaram e definiram as características do conhecer na área e os padrões de avaliação da produção acadêmica nessa racionalidade.

Figueiredo (1996) referenda a posição de Toulmin (1990), de que a busca de cientificidade esteve vinculada e subordinada à 
Molon, S. I.

"Algumas questões epistemológicas e éticas da psicologia: a avaliação em discussão"

política da certeza, que é a geração de dispositivos estabilizadores, reguladores, capazes de gerir racionalmente modos de viver e modos de pensar. Os que não se enquadram à política da certeza são criticados por renunciar ao rigor, à pesquisa e ao debate crítico.

Logo, configuram-se dois campos: os que fazem a ciência ${ }^{3}$ psicológica, básica e neutra, e os que fazem psicologia com compromisso político enfatizando a função social da ciência. Essa é uma falsa divisão, pois o que está presente são duas concepções de ciência, uma que segue o modelo positivista que ignora a subjetividade, e outra que resgata a subjetividade e rejeita a neutralidade e a objetividade.

Esse não é um fenômeno brasileiro nem latino-americano. Vygotsky (1996), em um texto de 1927, "O Significado histórico da crise da psicologia: uma investigação metodológica", fala da crise metodológica (epistemológica) da psicologia e da necessidade de criação de uma nova psicologia que ele definia como social. Para ele, as duas tendências existentes, a científico-natural-materalista e a espiritualista-descritiva, não conseguiam compreender o homem, pois o apanhavam de forma cindida e retalhada de acordo com suas crenças, quer sejam científicas quer sejam subjetivistas.

Sabemos que a psicologia moderna é um fenômeno caracteristicamente americano, seus produtores não exportaram para o mundo somente a predominância do experimentalismo e do individualismo, mas também um modelo de produção, aplicação e avaliação da produção do conhecimento e da concepção de universidade.

A Psicologia, o projeto de consolidação da psicologia como ciência, fortemente influenciado pela epistemologia positivista e naturalista, incorpora as dicotomias da ciência moderna e opera com reduçôes conceituais e metodológicas, eliminando a subjetividade e a afetividade do seu campo de investigação (MOLON, 1997).

É importante salientarmos que a crise é também decorrente desse modelo de ciência exportado para o mundo, que subjuga e subordina o conhecimento a um padrão imposto. Porém, nem to-

3 Esse debate é histórico na área da Psicologia, em especial na Psicologia Social, que protagonizou, na década de 80 , o confronto entre a posição positivista, modelo norte-americano, e a postura crítica da Psicologia desenvolvida na América Latina, Molon (2002), Lane e Sawaia (1991). 
dos se submetem a esse modelo, mas sofrem as suas implicações e repercussões.

Atualmente, a Psicologia apresenta dinamismo e intensa criatividade, manifestados pela expressiva produção em termos de conceitos, categorias teóricas e perspectivas metodológicas, em uma visão interdisciplinar. Essa riqueza e complexidade são caracterizadas pela diversidade e pluralidade de enfoques teórico-metodológicos e pela multiplicidade de modos de atuação e de intervenção, que geram uma produção significativa de experiências que são compartilhadas nos inúmeros eventos científicos internacionais, nacionais e regionais que acontecem freqüentemente, e nas publicaçôes em anais, cadernos de resumos, em revistas e nos periódicos, além das publicaçōes de livros e coletâneas.

Diante disso, muitas das produções e atuações da psicologia foram e estão sendo construídas na América Latina, como enfatizam Campos (1998), Montero (1994, 1996), Munné (1997) e Sawaia (1999), que rompem com a tradição da psicologia americana e européia. Nesse contexto, a questão da cientificidade da psicologia emerge com muita força dentre as suas áreas e entre os vários campos do conhecimento, pois nas universidades ocorreu a importação da ciência americana e também do modo de pensar e fazer americano, conseqüentemente, do modo de avaliar americano.

Essas questões estão presentes na Psicologia, mas não foram criadas no seu interior. $\mathrm{O}$ modelo de racionalidade científica constituiu-se a partir da revolução do século XVI e foi desenvolvido nos séculos seguintes, fundamentalmente no domínio das ciências naturais. Santos (1996) analisa detalhadamente a consolidação do paradigma dominante da ciência, sua crise e a construção do paradigma emergente. Localizamo-nos na luta pela emergência e consolidação de um outro modo de nos relacionar com o conhecimento: essa outra política tem implicações com a vida, com a subjetividade, com o belo, o bom e o justo.

O rigor científico que criticamos é o fundamentado no rigor matemático que ao quantificar os fenômenos os desqualifica, pois impõe o etnocentrismo, o que traz novamente à discussão a relação sujeito e objeto nas ciências humanas e sociais. 
Molon, S. I.

"Algumas questões epistemológicas e éticas da psicologia: a avaliação em discussão"

Santos (1996), ao se referir ao paradigma emergente, afirma que todo o conhecimento caracteriza-se por ser científico-natural e científico-social, local e total, conhecimento e autoconhecimento, e por visar a constituir-se em senso comum. Para afirmar suas idéias, lançou recentemente o livro "Crítica da razão indolente contra o desperdício da experiência”. Suas contribuições são extremamente significativas no sentido da compreensão e decodificação do paradigma da modernidade e do entendimento dos movimentos de transição e de contraposição a esse modelo, na busca e orientação de um outro referencial que considere primordialmente os projetos de emancipação social, a felicidade e a justiça.

O paradigma emergente não se limita a superar as dicotomias entre ciências naturais, duras e exatas, e as ciências humanas e sociais, nem as outras dicotomias presentes na psicologia: objetividade e subjetividade, corpo e mente, natural e cultural, objeto e sujeito, razão e emoção, indivíduo e sociedade, exclusão e inclusão.

O novo paradigma apresenta outra construção. Vygotsky (1996) diz que "a pedra que rejeitaram os construtores, esta veio a ser a pedra angular...” (p. 203). Nessa mesma direção, Santos (1996) afirma "o sujeito, que a ciência moderna lançara na diáspora do conhecimento irracional, regressa investido da tarefa de fazer erguer sobre si uma nova ordem científica” (p. 43).

O sujeito, a subjetividade, as emoçôes, o desejo, a invenção, a criatividade orientam a construção de um novo conhecimento e de um novo senso comum, ou seja, tudo que foi considerado obstáculo ao saber exato, as interferências afetivas, subjetivas, místicas e psicológicas, e, portanto, excluídos do cenário científico, é o que possibilita a construção de um novo conhecimento.

Para Sawaia (1998) e Molon (2000), a indagação a respeito do sujeito pode ser o eixo norteador da revisão crítica de várias áreas do conhecimento, especialmente da psicologia, pois a discussão sobre o lugar do sujeito - sujeito determinado, homogêneo, uniforme, mero reflexo da realidade, competência lingüística, imanência psíquica, abstraído da sociedade, mônada pensante - é o começo de um caminho produtivo e promissor para a crítica epistemológica que é simultaneamente ética e ontológica. Queremos investigar as 
novas formas de conhecer na perspectiva de uma interface entre ética, estética e política.

No momento em que o sujeito pode ser visto na processualidade e a produção dos diferentes modos de subjetivação são pesquisados, em que acontece o desenvolvimento das pesquisas participativas, qualitativas e quantitativas, que podemos conceber o fenômeno psicológico como uma construção social e histórica, que as diversas correntes e tendências da Psicologia trabalham na perspectiva da pesquisa e de um outro rigor, nossa luta e resistência permanecem no campo epistemológico e das práticas psicológicas, uma vez que estamos sendo desafiados a denunciar e enfrentar outros obstáculos e imposição na produção e na avaliação do nosso conhecimento.

Se rompermos com a metáfora da máquina perfeita, no modelo da estabilidade, ordem e equilíbrio, e com a teoria do um, como enfrentaremos o pensamento único que subsidia a produção e a avaliação do conhecimento em uma única direção de análise para situaçōes e organizações curriculares tão diferentes como são as realidades dos distintos programas de pós-graduação existentes no País?

O sistema de avaliação pressupõe a possibilidade de controlar o tipo de gestão administrativa do programa e da atuação dos docentes e dos discentes a partir de um único modelo de organização curricular e de condiçôes iguais para situaçōes e contextos diversos. Esse sistema de avaliação promoveu uma cisão entre a avaliação individual e avaliação institucional, "cisão no entanto necessária para fazer da avaliação um instrumento de concorrência e punição, no quadro geral de integração da universidade ao processo privatizante e elitizante" (COGGIOLA, 2001, p. 11). Tais questões estão diretamente implicadas com a condição da educação e da universidade na sociedade brasileira.

Os caminhos e descaminhos traçados para a educação pública brasileira, marcados pelas diversas iniciativas e concretizaçōes de açōes e estratégias políticas que comprometem o desenvolvimento e a qualidade da educação no País, exigem nosso empenho contra todas as formas de pressão e de opressão, quantificáveis e simbólicas, que desviam e desqualificam os compromissos e os princípios históricos com o projeto democrático de educação pública, gratuita e de qualidade para toda a população. 
Molon, S. I.

"Algumas questões epistemológicas e éticas da psicologia: a avaliação em discussão"

Assim, cabe-nos denunciar a submissão da política educacional às imposições e às orientaçôes dos organismos financeiros internacionais. $\mathrm{O}$ modelo de avaliação em curso pode ser uma das respostas às exigências do FMI e do Banco Mundial, agências controladoras que defendem a privatização da educação e das pesquisas.

Ianni (1997) chama a atenção para a visão mercadológica do governo, a qual busca reformar e transformar a universidade brasileira baseada em termos restritamente econômicos. Por isso, faz uso de um instrumento, o diagnóstico, que é visto meramente no sentido técnico, comprometido com a produtividade (competência e excelência), eficácia e competitividade. Para o autor, ao introduzir a concepção empresarial na educação, o Estado tende a "satanizar para mutilar, para induzir à privatização, para induzir a um tecnicismo economicista, para colocar a universidade a serviço da empresa privada, para tornar a universidade uma empresa privada" (p. 32).

O Estado deve responsabilizar-se pela educação, ensino/pesquisa/extensão, pelo oferecimento das condiçôes materiais - bibliotecas, laboratórios, sistema de bolsas e de auxílios - compatíveis com as necessidades da população e com as exigências de uma verdadeira educação de qualidade; além das condições salariais dos docentes e funcionários técnico-administrativos. O Ministério da Educação deve administrar o funcionamento do ensino, isto é, a maneira pela qual funciona o sistema de ensino está diretamente relacionada às políticas públicas educacionais.

No momento em que o Estado não provê as condições necessárias para a pesquisa, a iniciativa privada passa a financiá-la determinando o espaço, o tempo, o tema, o investimento a ser efetivado, destituindo o caráter de universalização do conhecimento e instituindo o abandono do princípio ético da liberdade, da responsabilidade e da criatividade, subordinando a produção do conhecimento à lógica do mercado, demanda e oferta, ao mercado volúvel e descartável.

Nessa discussão, Chauí (1995) diz que, com relação aos financiamentos das pesquisas, há uma tendência à aceitação à crítica da privatização das pesquisas, o que produz os seguintes efeitos: 
$\overline{=}$ Psicologia \& Sociedade; 16 (1): 108-123; Número Especial 2004

A - perda da autonomia ou liberdade universitária para definir prioridades, conteúdos, formas, prazos e utilização das pesquisas que se tornam inteiramente heterônomas; $B$ - aceitação de que o Estado seja desincumbido da responsabilidade pela pesquisa nas instituiçôes públicas; $C$ - aceitação dos financiamentos privados como complementação salarial e fornecimento de infra-estrutura para os trabalhos de investigação, privatizando a universidade pública; D - desprestígio crescente das humanidades, uma vez que sua produção não pode ser imediatamente inserida nas forças produtivas, como os resultados das ciências; $E$ - aceitação da condição terceiro-mundista para a pesquisa cientifica, uma vez que os verdadeiros financiamentos para a pesquisa de longo prazo e a fundo perdido são feitos no Primeiro Mundo. Com relação aos órgãos públicos de financiamento, como a CAPES, CNPq ou FINEP, sabe-se que a burocracia desses órgãos absorve a maior parte dos recursos em sua auto-reprodução... (pp. 86-87).

Esses efeitos abordados por Chauí, em seu texto de 1995, estão cada dia mais presentes no nosso cotidiano, em que a autonomia das universidades brasileiras vem sendo constantemente violentada pela imposição da lógica do mercado e dos interesses internacionais, instalando a alienação e a heteronomia no contexto universitário (MANCEBO, 1998).

Cada vez mais, o Estado não se compromete nem se responsabiliza pelas condições geradoras e de manutenção da educação pública, ao mesmo tempo em que cria sistematicamente mecanismos de avaliação do sistema educativo, por exemplo, o Sistema de Avaliação da Educação Básica (Saeb), o Exame Nacional do Ensino Médio (Enem); o Provão, comissão de especialistas para avaliar as condiçōes de oferta e de demanda dos cursos de graduação; comissões de avaliação da pós-graduação; avaliação interna e externa (institucional) da universidade; etc.. As atuais políticas de avaliação estão centralizadas nos resultados, objetivam medir resultados e estabelecer o ranking das áreas do conhecimento e nos diversos níveis de ensino, gerando mais um instrumento de regulação social do Estado. 
Molon, S. I.

"Algumas questões epistemológicas e éticas da psicologia: a avaliação em discussão"

Nossa história de pós-graduação é recente, o sistema de avaliação implantado pela CAPES data de 1976 e foi inspirado no modelo americano de credenciamento, no início dos anos 70. A preocupação central era medir a qualidade dos cursos de mestrado e doutorado, objetivando determinar os que deveriam receber financiamento, ou melhor, receber apoio financeiro da agência.

O resultado é o mais importante na avaliação? Perguntamos: o que predomina é a política da certeza? O que buscam as agências de fomento e controle da pesquisa no Brasil é o fortalecimento da construção e da legitimação de procedimentos disciplinares: a exacerbação da regulamentação e do controle, explícito e simbólico, dentro e fora da área psicológica, para saber quem somos, o que fazemos, qual o valor de cada coisa feita? Onde publicamos? Qual o conceito do Programa que trabalhamos? Qual o conceito da revista que publicamos?

Temos de estar cientes de que o Estado avaliador é ao mesmo tempo o legislador e o juiz, mas nunca se coloca como responsável pela qualidade educacional, e o que é mais sintomático:

A destruição planejada e sistemática da autonomia universitária deixou um trágico saldo de instituiçôes desmoralizadas e irresponsáveis. Projetos mais consistentes de avaliação não podem ignorar o fato de que dado o nivel de incapacitação legal a que foram compulsoriamente levadas, pouco se pode debitar às universidades das ineficiências e irracionalidades pelas quais são rotineiramente responsabilizada. (COELHO, 1996, p. 32)

O gestor e o avaliador consideram o desempenho do docente, do pesquisador, do discente, mas ignoram o descomprometimento dos órgãos governamentais e do Estado. Por conseguinte, a responsabilidade é do docente para conseguir a produtividade cada dia mais requintada e exigente.

Embora existindo um aparente esgotamento da racionalidade hegemônica, há, ao mesmo tempo, um acirramento da lógica capitalista excludente e dominadora, que se mostra perversamente eficiente na sua lógica de culpabilização do indivíduo e dos grupos sociais por esses desmandos e desmantelamentos das suas instituiçóes. 
Entretanto, as experiências docentes e discentes evidenciam um compromisso com a transformação dessa realidade. As indagações sobre as repercussóes dos projetos de pesquisa na comunidade ou no grupo pesquisado são constantes, bem como as possibilidades de alteração das condições de vida dos sujeitos, eles e nós. Apesar das precárias e miseráveis condições e situações, o trabalho universitário tem um compromisso com a criatividade, com a imaginação, com o desejo, com a potência de ser e vir a ser, com a elaboração das idéias, com a invenção e com a perspectiva utópica.

Uma vez mais, recorremos a Santos (1996a), quando diz que nossas interrogações, nossa indignação e nosso espanto combatem a trivialização e a banalização do sofrimento humano. Sawaia (1999) nos ajuda com a construção de um referencial teórico e metodológico, a categoria do sofrimento ético-político, que se refere às injustiças e à dor mediada pela desigualdade social e pela lógica perversa da exclusão e inclusão social.

Diante disso, estamos todos(as) afetados(as) pela lógica capitalista que define perversamente os excluídos e os incluídos, e vivemos o sofrimento ético-político. Considerando que a privatização não é só a da universidade, as reformas do Estado, as imposições do FMI e do Banco Mundial atingem vários segmentos da sociedade.

Cabe-nos, ainda, reconhecer o trabalho árduo e eficiente dos nossos colegas em aprimorar a análise dos quesitos, indicadores e critérios, os procedimentos atuais e propor alteraçōes no que se refere a novos elementos de análise e ao fluxo de informaçóes, sugerindo a verificação do movimento processual das informaçôes coletadas. Podemos continuar trabalhando nessa perspectiva e até reconhecermos alguns avanços no sistema de avaliação, mas estaremos subordinados à política da certeza, aos interesses dos organismos de financiamento internacional, e sistematicamente promovendo o fortalecimento da política imposta à educação brasileira, por meio da sustentação dos centros de excelência, da desintegração dos diferentes níveis da educação, da impossibilidade de atuar no tripé da universidade que é a articulação entre ensino, pesquisa e extensão, além das práticas culturais.

$\mathrm{Na}$ visão mercadológica, o que fazer com as atividades de extensão que não visam à captação de recursos, mas sim ao compro- 
Molon, S. I.

"Algumas questões epistemológicas e éticas da psicologia: a avaliação em discussão"

metimento das instituições com a população, por meio do engajamento nos projetos criativos de ensino, pesquisa e extensão que potencializam o ser e a vida?

Outra possibilidade é pensarmos na reconstrução da universidade pública, na perspectiva de construção do conhecimento pautado pelo projeto democrático e coletivo da educação emancipatória, implicada com a felicidade, a justiça, a liberdade, contemplando a diversidade do conhecimento, a pluralidade de modos de atuação, de intervenção e de invenção. Nas palavras de Santos (2000) lutamos pela produção do "saber militante".

O processo avaliativo deve se pautar em uma construção coletiva, criada no diálogo entre os diversos sujeitos (os atores sociais representantes dos mais amplos segmentos da sociedade, das universidades, do fazer público, das políticas educacionais, das várias associaçōes - científicas, profissionais, sindicais -, fóruns, entidades, etc.).

O processo de avaliação dos programas de pós-graduação, mestrados e doutorados deve ser pensado e efetivado em uma perspectiva que respeite plenamente a autonomia universitária, contemplando amplamente o exercício da liberdade acadêmica e científica. Como também, na perspectiva de responsabilidade e de comprometimento dos órgãos governamentais, no âmbito das políticas educacionais de qualificação da pós-graduação e do aperfeiçoamento das condições institucionais.

Nessa perspectiva, enfrentamos o desafio de criar, inventar e produzir novos modos de conhecer, os diversos e diferentes sujeitos de investigação e as produções de subjetividade. Essa construção partilhada propicia e recorre das múltiplas apropriaçôes e dos diferentes interesses; não é mais o resultado de um trabalho de um autor isolado ou de uma comissão de especialistas das áreas interna e externamente instituídas, mas a prática teórica implicada com os seres humanos, com suas condições de vida e de morte, e com as complexas relaçōes institucionais, interinstitucionais e não instituídas.

Portanto, convocamos todos os sujeitos a defender o princípio ético-democrático do direto à educação. Nessa luta, de combate e de resistência, a Psicologia tem um papel fundamental, pois a sua riqueza e diversidade teórica e metodológica, sua multiplicidade de 
Psicologia \& Sociedade; 16 (1): 108-123; Número Especial 2004

atuação e intervenção, junto com a questão do sujeito e da produção da subjetividade, pode produzir e construir novos modos de conhecer e novas práticas sociais e institucionais baseadas na comunicação e na solidariedade, na perspectiva da interface entre ética, estética e política, tornando nossa ciência capaz de contribuir para que a vida seja mais justa, digna e feliz, e para a invenção de novos modos de subjetivação.

\section{REFERÊNCIAS}

CAMPOS, Regina. H. F. Entrevista: A característica cultural latinoamericana que tem desafiado os analistas é precisamente a sua pluralidade. Psicologia \& Sociedade. São Paulo, ABRAPSO, v.10, n 2, pp. 5-18, jul./dez., 1998.

CHAUÍ, Marilena. Ética e universidade. Universidade e Sociedade. ano V, nº 8, pp. 82-87, fev. 1995.

COELHO, Edmundo C. Zerando o passado, avaliando as universidades. Monitor Público, Rio de Janeiro, ano 3, n ${ }^{\circ} 11$, pp.31-35, dez. 1996.

COGGIOLA, Osvaldo. Políticas públicas, políticas privadas e avaliação. Universidade e Sociedade. ano X, n 23, pp.7-13, fev. 2001.

FIGUEIREDO, L. C. M. Matrizes do Pensamento Psicológico. Petrópolis, RJ, Vozes, 1991.

FIGUEIREDO, L. C. M. A invenção do psicológico: quatro séculos de subjetivação (1500-1900). São Paulo, Educl Escuta, 1992.

FIGUEIREDO, L. C. M. Revisitando as psicologias: da epistemologia à ética das práticas e discursos psicológicos. São Paulo, Educ, Petrópolis, Vozes, 1996.

GONZÁLEZ REY, Fernando. Epistemología cualitativa y subjetividad. São Paulo, Educ, 1997.

GONZÁLEZ REY, Fernando. La investigación cualitativa en psicologia: rumbos y desafios. São Paulo, Educ, 1999. 
Molon, S. I.

"Algumas questões epistemológicas e éticas da psicologia: a avaliação em discussão"

IANNI, Octavio. A visão mercadológica do governo e o distanciamento da sociedade. Universidade e Sociedade, ano VII, n 12 , pp. 30-35, fev. 1997.

LANE, Silvia T. M. e SAWAIA, Bader B. Psicologia: ciência ou política ? In: MONTERO, Maritza (coord.) Acción y discurso-problema de psicología politica en América Latina. Venezuela, Eduven, 1991.

MANCEBO, Deise. Autonomia universitária: reformas propostas e resistência cultural. Universidade e Sociedade, ano VIII, $\mathrm{n}^{\circ} 15$, pp. 51-59, fev. 1998.

MOLON, Susana I. O processo de exclusão/inclusão na constituição do sujeito. In: ZANELLA, Andréa. et al. Psicologia e práticas sociais. Porto Alegre, ABRAPSOSUL, 1997.

MOLON, Susana I. Sujeito, subjetividade e emoções: na perspectiva dos professores da pós-graduação em psicologia social vinculados à ABRAPSO. São Paulo, Tese de doutorado, PUC, 2000.

MOLON, Susana I. A psicologia social abrapsiana: apontamentos históricos. Interaçôes: Estudos e pesquisas em Psicologia. São Paulo, Unimarco, v. VI, n 12. pp. 41- 68, jul./dez. 2001, 2002.

MONTERO, Maritza. Un paradigma para la psicología social. Reflexiones desde el quehacer en América Latina. In: MONTERO, Maritza. (coord.) Construcción y crítica de la psicología social. Barcelona, Anthropos; Caracas, Universidad Central de Venezuela, 1994.

MONTERO, Maritza. Paradigmas, corrientes y tendencias de la psicología social finisecular. Psicologia \& Sociedade. São Paulo, ABRAPSO, v. 8, nº 1, pp. 102-119, jan./jun., 1996.

MUNNÉ, Frederic. Psicologías sociales marginadas: la linea de Marx en la psicología social. Barcelona, Hispano Europea, 1982.

MUNNÉ, Frederic. Pluralismo teórico y comportamiento social. Psicologia \& Sociedade. São Paulo, ABRAPSO, v. 9, n.1/2, pp. 31-46, jan./dez. 1997.

SANTOS, B. de S. Um discurso sobre as ciências. Porto, Afrontamento, 1996. 
Psicologia \& Sociedade; 16 (1): 108-123; Número Especial 2004

SANTOS, B. de S. Para uma pedagogia do conflito. In: SILVA, L. E. da. Reestruturação curricular: novos mapas culturais, novas perspectivas educacionais. Porto Alegre: Sulina, 1996a.

SANTOS, B. de S. A crítica da razão indolente. Contra o desperdício da experiência. São Paulo, Cortez, 2000.

SAWAIA, Bader B. Psicologia social: aspectos epistemológicos e éticos. In: LANE, Silvia T. M. e SAWAIA, Bader B. (orgs.) Novas veredas da psicologia social. São Paulo, Brasiliense, Educ, 1995.

SAWAIA, Bader B. A crítica ético-epistemológica da psicologia social pela questão do sujeito. Psicologia \& Sociedade. São Paulo, ABRAPSO, v. 10, nº 2, pp.117-136, jul./dez. 1998.

SAWAIA, Bader B. As artimanhas da exclusão: análise psicossocial e ética da desigualdade social. Petrópolis, RJ : Vozes, 1999.

TOULMIN, S. Cosmopolis. The hidden agenda of modernity. Chicago, University Press, 1990.

VYGOTSKY, Lev. S. Teoria e método em psicologia. São Paulo, Martins Fontes, 1996.

VYGOTSKY, Lev. S. A construção do pensamento e da linguagem. São Paulo, Martins Fontes, 2001.

Susana Inês Molon é Professora Adjunto do Departamento de Educação e Ciências do Comportamento da Fundação Universidade Federal do Rio Grande (FURG). Docente do programa de mestrado em Educação Ambiental. O endereço eletrônico da autora é: susanamolon@furg.br

Susana Inês Molon

Algumas questões epistemológicas e éticas da psicologia: a avaliação em discussão Recebido: $18 / 11 / 2003$

$1^{\text {a }}$ revisão: $8 / 4 / 2004$

Aceite final: 3/5/2004 